MIMBAR

JURNAL PENELITIAN SOSIAL DAN POLITIK

\title{
ANALISIS FENOMENA KERENTANAN RUMAH TRADISIONAL MASYARAKAT KOBE DENGAN RUMAH TRADISIONAL MASYARAKAT LOMBOK TERHADAP BENCANA GEMPA BUMI
}

\author{
Aries Munandar ${ }^{1}$ \\ Email : Arys_munandar@yahoo.com
}

\begin{abstract}
ABSTRAKS
Progres peningkatan kesejahteraan sosial melalui pembangunan sering kali terganggu karena kejadian bencana gempa bumi. Gempa bumi menyebabkan kehancuran bangunan rumah masyarakat secara massif. Namun terdapat fenomena yang kontradiktif berkaitan dengan kehancuran rumah tradisional masyarakat di Kobe dengan rumah tradisional masyarakat di Lombok ketika mengalami guncangan gempa bumi. Oleh karena itu penelitian ini berusaha untuk menemukan jawaban tentang keadaan kerentanan struktur rumah tradisional dan rumah non tradisional masyarakat di Kobe dan di Lombok. Penelitian ini juga mengidentifikasi prinsipprinsip dasar pengurangan risiko kehancuran akibat bencana gempa bumi. Penelitian dilakukan dengan membandingkan struktur yang umum dipergunakan pada rumah tradisional dan rumah non tradisional di kedua daerah tersebut.

Hasil analisa menunjukkan bahwa rumah tradisional masyarakat Lombok dan rumah non tradisional masyarakat Kobe cenderung lebih tahan terhadap ancaman gempa bumi, karena posisi titik berat bangunan yang lebih rendah, sebagai akibat dari penggunaan bahan atap rumah yang lebih. Prinsip dasar untuk pengurangan risiko kehancuran bangunan rumah dari guncangan gempa bumi adalah dengan : penguatan bahan bangunan yang digunakan, penguatan sambungansambungan pada pilar balok penyangga, menempatkan titik berat bangunan rumah sedekat mungkin dengan tanah, dan meningkatkan elastisitas bangunan terhadap guncangan.
\end{abstract}

Keywords : Bencana Gempa Bumi, Kerentanan Rumah Tradisional, Gempa Bumi Lombok

\footnotetext{
${ }^{1}$ Dosen Prodi Ilmu Kesejahteraan Sosial Fisip Universitas Bengkulu
} 
MIMBAR

JURNAL PENELITIAN SOSIAL DAN POLITIK

\section{A. Pendahuluan}

Gempa bumi merupakan salah satu kejadian alamiah yag menjadi sifat bumi. Gempa bumi dapat terjadi akibat fenomena geologis maupun fenomena vulkanologis. Pada daerah-daerah rawa gempa bumi seperti di Jepang, dan Indonesia, gempa bumi dapat sangat sering terjadi. Namun hanya gempa bumi dengan magnitude besar lah yang hampir selalu mendatangkan bencana bagi umat manusia.

Dampak yang ditimbulkan oleh gempa bumi bukan saja berupa robohnya bangunan ataujatuhnya korban manusia secara parsial. Tetapi dampak dari gempa bumi dapat menyebabkan kehancuran menyeluruh yang bersifat massif pada sebuah kawasan baik perkotaan maupun pedesaan dengan segenap infrastrukturnya.

Kehancuran mengganggu

kehidupan dan kesejahteraan masyarakat di lokasi terjadinya bencana gempa bumi tersebut. Dengan gempa bumi yang terjadi hanya dalam beberapa menit saja dapat berakibat menghancurkan capaian kesejahteraan sosial yang sudah dibangun puluhan tahun dan mengembalikan masyarakat terdampak pada kesengsaraan.

Beberapa kejadian gempa bumi yang termasuk dalam kategori sebagai penyebab bencana terbesar di dunia, diantaranya adalah gempa bumi di Chilli tahun 1960, gempa bumidi Alaska tahun 1964, Kobe tahun 1995, gempa bumi di Tohotahun 2011, dan gempa bumi di Acehtahun 2004. Masing-masing kejadian gempa bumi tersebut telah menyebabkan kematian puluhan ribu orang.

Pada tahun 2018, Indonesia dilanda dua kali gempa bumi dengan magnitude cukup besar, yaitu Gempa Bumi Lombok Provinsi Nusa Tenggara Barat yang terjadi pada bulan Agustus sampai dengan September 2018 - dengan magnitude 6,4 Skala Richter dan gempa bumi Palu Sulawesi Tengah pada bulan Oktober 2018 dengan magnitude yang mencapai 7,7 Skala Richter.

Hasil pengamatan peneliti menunjukkan bahwa, pada kejadiankejadian bencana gempa bumi tersebut, hasil teridentifikasi bahwa jatuhnya korban jiwa sesungguhnya lebih banyak disebabkan oleh karena tertimpa bangunan, baik itu bangunan rumah tinggal, bangunan kantor, bangunan tempat ibadah, gedung sekolah atau gedung pusat keramaian lainnya seperti hotel, pusat perbelanjaan, pasar, terminal, stasiun dan sebagainya.

Kasus korban jiwa akibat tertimpa bangunan banyak terjadi karena kejadian gempa bumi terjadi tiba-tiba dan tidak terduga. Pihak pemerintah pun tidak dapat berbuat banyak karena hingga saat ini belum ditemukan peralatan yang dapat mendeteksi secara pasti kapan sebuah kejadian gempa bumi akan terjadi dan seberapa besar guncangannya. Keadaan ini sangat berbeda dengan ancaman bencana alam lainnya seperti banjir, angin badai, cuaca ekstrim atau pun tanah longsor yang lebih mudah diperkirakan kejadiannya (Munandar, 2015).

Pada kasus gempa bumi di Kobe yang terjadi pada tanggal 17 Januari 1995 dengan magnitude 7,2 Skala Richter tersebut, sebenarnya pusat pemantauan gempa bumi di Jepang sudah mendeteksi adanya gejala peningkatan frekuensi getaran gempa pada radius $15 \mathrm{~s} / \mathrm{d} 20 \mathrm{~km}$ dari Kota Kobe. Namun mereka tidak menemukan alasan bahwa getaran tersebut justrumenyebabkan terjadinya gempa besar di kota Kobe. Sehingga tidak cukup alasan bagi Pemerintah Kota Kobe pada masa itu untuk memberikan peringatan kewaspadaan kepada warganya.

Hasil post disaster invertigation yang dilakukan oleh Pemerintah Jepang menemukan bahwa kejadian bencana gempa bumi di Kobe tersebut telah menyebabkan lebih dari 5000 orang meninggal dunia, disamping yang luka-luka. Setelah dilakukan pemetaan yang lebih jauh, kemudian diketahui bahwa dari jumlah korban meninggal tersebut, mayoritas berada di zona pinggiran Kota Kobe pada kawasan masih banyak terdapat perumahan penduduk dengan struktur konstruksi tradisional setempat. Para korban umumnya meninggal karena tertimpa bangunan rumah mereka sendiri yang masih merupakan bangunan tradisional. Sedangkan pada bangunan dan perumahan modern yang dibangun di tengah kota, konstruksisudah dibuat lebih tahan terhadap gempa bumi sehingga meskipun bangunanya rusak namun relatif tidak sampai banyak membunuh penghuni di dalamnya.

Kejadian ini berbanding terbalik dengan fenomena yang terjadi pada gempa 


\section{MIMBAR}

JURNAL PENELITIAN SOSIAL DAN POLITIK

bumi Lombok pada 30 Juli 2018. Berdasarkan pengamatan langsung peneliti saat menjadi relawan yang dilengkapi pula dengan data dari Badan Nasional Penanggulangan Bencana (BNPB) dan Badan Penanggulangan Bencana Daerah Provinsi Nusa Tenggara Barat, ditemukan kenyataan bahwa rumah tradisional masyarakat Lombok ternyata merupakan bangunan yang justru paling minim terdampak kejadian gempa bumi tersebut. Sehingga masyarakat Sasak (Suku Asli Lombok) yang masih menghuni dan tinggal di rumah tradisional khas mereka dapat selamat dari bahaya reruntuhan bangunan rumah mereka. Bahkan rumah tradisional tersebut sama sekali tidak roboh ataupun rusak.

Hasil penelitian lain menunjukkan bahwa bangunan Berugak yang merupakan bangunan domestik khas masyarakat Lombok ternyata sangat tahan guncangan gempa bumi. Pada masa darurat bencana gempa bumi Lombok tahun 2018, bangunan Berugak tersebut teridentifikasi mengalami perluasan fungsi menjadi shelter yang efektif sebagai tempat berlindung dan melakukan aktifitas sosial kedaruratan (baca : Munandar et. al, 2018).

Sebaliknya, rumah-rumah masyarakat umum di Lombok yang tidak menggunakan sistem konstruksi tradisional mengalami kehancuran yang massive. Bahkan keadaan yang ironis terjadi di banyak tempat, dimana pada satu kawasan perkampungan rumah-rumah yang dibangun dengan struktur tradisional tetap tegak berdiri sementara tepat disebelahnya bangunan dengan struktur non tradisional ambruk.

Adanya fenomena yang mengindikasikan kontradiksi antara rumah tradisional masyarakat di Kobe dengan rumah tradisional masyarakat di Lombok, penulis merasa perlu untuk meneliti dan mendalami bagaimana fenomena tersebut dapat terjadi.

\section{B. Metode Penelitian}

Desain penelitian ini adalah kualitatif deskriptif. Pengumpulan datatentang dampak bencana gempa bumi di Kobe dilakukan dengan studi dokumen dan studi pustaka. Sedangkan untuk mendapatkan data dan informasi terkait dampak gempa bumi di Lombok dilakukan dengan observasi lapangan yang dilakukan secara langsung oleh peneliti, dan dilengkapi pula dengan studi dokumen.

Analisis data dilakukan dengan membandingkan struktur yang umum dipergunakan pada umum bangunan rumah tradisional masyarakat Kobe tahun 1995 dengan rumah tradisional masyarakat Lombok. Proses perbandingan akan melihat mengidentifikasi struktur konstruksi rangka, dindingdan bahan atap yang dipergunakan pada kedua macam rumah tradisional tersebut. Meskipun berada pada masa waktu yang berbeda namun indikator dengan kualifikasi yang sama sebagaihasil kearifan setempat di masyarakat masing-masing, sehingga dapat memenuhi kriteria perbandingan apple to apple.

Sebagai pelengkap studi komparasi, peneliti juga membandingkan antara rumah non tradisional masyarakat di Kobe pada saat kejadian bencana Gempa Bumi tahun 1995 dengan rumah non tradisional masyarakat di Lombok pada saat kejadian gempa bumi tahun 2018. Rumah non tradisional di definisikan sebagai rumah tinggal yang dibangun masyarakat dengan menggunakan struktur bangunan yang lebih modern dan atau mengikuti perkembangan jaman yang berbeda dengan struktur yang biasa digunakan untuk membangun rumah tradisional setempat.

\section{Hasil Penelitian}

Dari hasil pencermatan diketahui bahwa terdapat beberapa kesamaan dan perbedaan antara konstruksi pokok bangunan rumah tradisional masyarakat di Kobe dengan di Lombok.

Pada struktur rumah tradisional masyarakat Kobe,pilar tiang atau balok penyangga utama rumah dibuat dari bahan kayu. Struktur dinding rumah dibuat menempel ke tiang atau balok utama.Bahan untuk dindingdapat terbuat dari struktur campuran beton dan bambu atau bahan lainnya. Menurut ahli konstruksi bangunan sebagaimana dinyatakan dalam video dokumenter pada media youtube (2016) dinding pada rumah tradisional Kobe dianggaptidak bersifat memperkuat konstruksi dari tiang atau balok penyangga utama atau konstruksi rumah secara keseluruhan. Analisis tersebut juga mengungkapkan bahwa atap rumah 


\section{MIMBAR}

JURNAL PENELITIAN SOSIAL DAN POLITIK

tradisional masyarakat Kobe yang pada umumnya terbuat dari bahan genting tanah dan sering pula disertai dengan asesoris khas setempat memiliki berat yang mencapai 2000 kilogram bahkan lebih. Beban tersebut sangat membebani tiang atau balok utama konstruksi rumah yang sudah tidak diperkuat oleh struktur dindingnya.

Keadaan tersebut menyebabkan terjadinya ketidakseimbangan titik berat pada bangunan rumah dimana struktur bagian atas rumah menjadi ebih berat daripada bagian tengah dan bawah. Struktur yang labil ini menyebabkan bangunan rumah mudah ambruk, roboh atau terbalik.
Sementara bangunan rumah non tradisional masyarakat Kobe dibuat dengan konstruksi yang sudah mempertimbangkan tahan gempa berdasarkan aturan yang ditetapkan oleh pemerintah setempat. Oleh karena Kota Kobe merupakan kawasan perkotaan yang sudah cukup maju dan Pemeritah dan masyarakat Jepang sangat sadar bahwa wilayah mereka adalah daerah yang rawan gempa bumi maka pembangunan perumaham modern di daerah itu telah mengikuti struktur konstruksi bangunan yang tahan terhadap gempa bumi. Sehingga walaupun dengan dahsyatnya guncangan gempa bumi Kobe tahun 1995 bangunan-bangunan baru tersebut juga mengalami kerusakan, namun dapat

Gambar: 2

Ilustrasi Kerentanan Konstruksi Rumah Tradisional Masyarakat Kobe

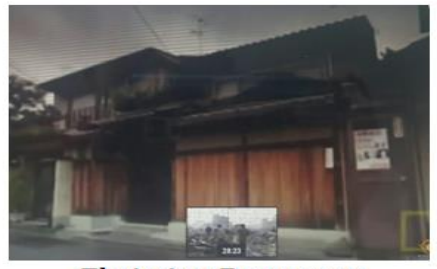

Eksisting Bangunan

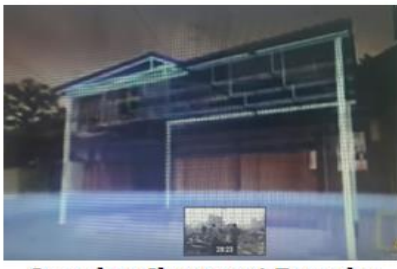

Overlay Ilustrasi Rangka



Eksisting Ilustrasi Rangka Sumber: National Geographic@youtube, 2016

Berdasarkan hasil investigasi dan penelitian yang diulas dalam video dokumenter pada media youtube (2016) terungkap pula bahwa alasan masyarakat Kobe membuat atap rumah mereka dari bahan genteng diantaranya adalah untuk membuatnya lebih tahan terhadap terpaan angin kencang. Bahan genteng sebagai atap dapat mengurangi potensi kerusakan atap bila terjadi typoon atau cuaca ekstrim lainnya.. meminimalisasi jatuhnya korban manusia.

Berdasarkan keterangan informan penelitian dari masyarakat yang menghuni rumah tradisional di Lombok, diketahui bahwa pada rumah tradisional masyarakat Lombok, pilar tiang utama dibangun dari bahanbalok kayu pilihan yang masingmasing bagiannya disatukan dengan semacam pasak / paku kayu. Tidak berbeda dari rumah tradisional masyarakat Kobe, dinding rumah masyarakat Lombok juga terbuat dari bahan bambu. Bahan bambu

Gambar: 3

Rumah Tradisional yang Ambruk oleh Gempa Bumi Kobe Akibat Beban Berat pada Atap Bangunan



Sumber: https://thecarpentryway.blog/2012/09/shaken-not-stirred/ 


\section{MIMBAR}

JURNAL PENELITIAN SOSIAL DAN POLITIK

tersebut diolah hingga menjadi lembaran dinding yang disebut bilik. Secara konstruksional bangunan, dinding seperti ini juga tidak dapat diandalkan untuk menambah kekuatan konstruksi tiang penyangga maupun konstruksi keseluruhan rumah. Namun bagian atap rumah terbuat dari bahan rumput yang disusun menggunakanteknik penganyaman yang khas, lalu yang diikatkan pada rangka rumah. Bahan rumput ini menyebabkan atap rumah tradisonal ini lebih ringan dan tidak membebani struktur dibawahnya. Struktur mana yang menyebabkan titik berat

bangunan rumah pun berada dekat dengan tanah dan banguna rumah dapat berdiri dengan stabil meskipun konstruksi atap nya

cukup tinggi.

Rumah non tradisional masyarakat Lombok pada umumnya merupakan bangunan 'rumah tumbuh'. Oleh karena keterbatasan keadaan ekonomi, masyarakat awam di Lombokumumnya membangun rumah secara bertahap. Pada tahapan awal mereka membangun rumah seadanya untuk sekedar memiliki tempat tinggal. Seiring perkembangan pendapatan, yang biasanya didapatkan dari hasil anggota keluarga bekerja di luar negeri,mereka berangsurangsur merenovasi atau melangkapi rumah awal mereka itu. Pada akhirnya rumah yang semula sangat darurat kemudian terlihat lebih layak dan lebih baik. Namun hal yang sering terlupakan adalah proses renovasi itu tidak diawali dengan perubahan atau peningkatan pondasi dan pilar dasar bangunan.Bagian atap rumah ysang selama ini ditutupi dengan bahan seng (Zing) seadanya tiba-tiba diganti dengan bahan genting yang berat yang menambah beban struktur pondasi bangunan. Pada saat terjadi gempa bumi struktur pondasi bangunan tidak cukup kuat menahan getaran dan beban bagian bangunan hasil renovasi tadi. Sehingga bangunan menjadi retak, ambruk dan kemudian benar-benar roboh.
Berdasarkan bahasan diatas, maka dapat dikomparasikan keadaan bangunan rumah masyarakat di Kobe pada masa terjadinya gempa bumi tahun 1995 dengan rumah masyarakat di Lombok pada masa terjadinya gempa bumi tahun 2018, sebagaimana tabel berikut ini :

Tabel : 1

Komparasi Kerentanan

Rumah Masyarakat Kobe dan Rumah Masyarakat Lombok terhadap Bencana Gempa Bumi

\begin{tabular}{|c|c|c|c|}
\hline & & $\begin{array}{c}\text { RUMAH } \\
\text { MASYARAKAT } \\
\text { KOBE }\end{array}$ & $\begin{array}{c}\text { RUMAH } \\
\text { MASYARAKAT } \\
\text { LOMBOK }\end{array}$ \\
\hline \multirow{5}{*}{$\begin{array}{l}\text { TR } \\
\text { A } \\
\text { DIS } \\
\text { I } \\
\text { ON } \\
\text { AL }\end{array}$} & bahan atap & Genteng & Rumput \\
\hline & $\begin{array}{l}\text { bahan } \\
\text { dinding }\end{array}$ & Campuran Bambu & Olahan Bambu \\
\hline & $\begin{array}{l}\text { bahan } \\
\text { rangka }\end{array}$ & Kayu & Kayu Lokal \\
\hline & $\begin{array}{l}\text { posisi titik } \\
\text { berat }\end{array}$ & Tinggi & Rendah \\
\hline & $\begin{array}{l}\text { dampak } \\
\text { gempa }\end{array}$ & Ambruk & Tidak Terpengaruh \\
\hline \multirow{5}{*}{$\begin{array}{l}\text { NO } \\
\text { N } \\
\text { TR } \\
\text { A } \\
\text { DIS } \\
\text { I } \\
\text { ON } \\
\text { AL }\end{array}$} & bahan atap & Variatif & Genteng \\
\hline & $\begin{array}{l}\text { bahan } \\
\text { dinding }\end{array}$ & Cenderung Beton & Cenderung Beton \\
\hline & $\begin{array}{l}\text { bahan } \\
\text { rangka }\end{array}$ & $\begin{array}{ll}\text { Beton } & \text { Tahan } \\
\text { Gempa } & \\
\end{array}$ & Beton \\
\hline & $\begin{array}{l}\text { posisi titik } \\
\text { berat }\end{array}$ & Rendah & Tinggi \\
\hline & $\begin{array}{l}\text { dampak } \\
\text { gempa }\end{array}$ & Lebih Tahan & Ambruk \\
\hline
\end{tabular}

Sumber : Hasil Analisis, 2018

Secara teoritis, tabel diatas mengilustrasikan bahwa ada pergeseran tingkat ketahanan bangunan pada masyarakat di Kobe dengan masyarakat di Lombok. Melalui pengalaman karena bencana gempa bumi sebelumnya, Masyarakat di Kobe telah berhasil menggeser kerentanan bangunan rumah tradisionalnya menjadi lebih tahan bencana gempa bumi pada bangunan rumah non tradisional yang lebih baru, melalui paket kebijakan standar bangunan oleh pemerintah setempat. Fenomena ini bersesuaian dengan

Gambar : 4

Rumah Tradisional Masyarakat Lombok Tidak Roboh Meskipun Rumah Non Tradisional Disebelahnya Hancur karena Gempa Bumi Tahun 2018

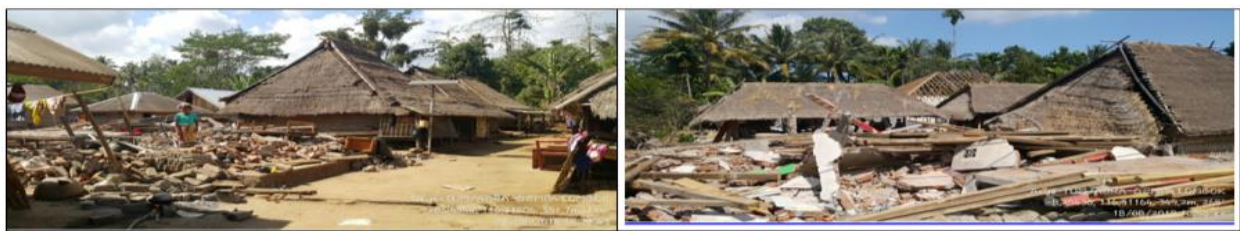


teori Carter (1991) yang dimodifikasi oleh Munandar (2015) dalam rangka manajemen penanggulangan bencana gempa bumi dan tsunami. Sementara di Lombok, masyarakat setempat justru sebaliknya. Penggunaan bahan yang kokoh, bahan atap yang ringan, posisi titik berat bangunan yang rendah menjadi kunci kekuatan bangunan rumah tradisional di lombok dan rumah non tradisional di Kobe.Secara teoritis, kekuatan struktur bangunan ini menjadi komponen preparesness dan mitigasi yang efektif untuk menghadapi ancaman bencana gempa bumi.Karena korelasi antara kerentanan bangunan dengan tingkat preparedness dan mitigasi bencana gempa bumi berbentuk perbandingan terbalik.

\section{Kesimpulan dan Saran \\ 1. Kesimpulan}

Pada penelitian ini berhasil didapatkan beberapa kesimpulan sebagai berikut : (1) Rumah tradisional masyarakat Lombok dan rumah non tradisional masyarakat Kobe cenderung lebih tahan terhadap ancaman gempa bumi. (2) Bahan atap rumah yang berat cenderung menambah tinggi posisi titik berat dari bangunan rumah, yang berkorelasi terhadap ketahanan rumah tersebut dari guncangan gempa bumi. (3) Bahan kayu yang memiliki elastisitas yang cukup tinggi pada bangunan rumah tradisional perlu juga didukung oleh beban bagian atap rumah yang lebih ringan agar bangunan rumah lebih tahan terhadap guncangan gempa bumi dan tsunami. (4) Fenomena ketahanan bangunan rumah tradisional masyarakat Lombok terhadap guncangan gempa bumi dapat dijadikan rujukan untuk mengembangkan teknologi 'rumah aman gempa' di daerah rawan bencana gempa bumi. (5) Beberapa usaha yang dapat dilakukan untuk meningkatkan ketahanan bangunan rumah terhadap guncangan gempa bumi adalah dengan : penggunaan bahan atap rumah yang lebih ringan, peningkatan kekuatan pondasi dan pilar-pilar tiang / balok penyangga bangunan rumah, penggunaan bahan dinding rumah yang dapat berfungsi menopang dan memperkuat pilar-pilat penyangga bangunan rumah. (6) Prinsip dasar untuk pengurangan risiko kehancuran bangunan rumah dari guncangan gempa bumiadalah dengan : penguatan bahan bangunan yang digunakan, penguatan sambungan-sambungan pada pilar balok penyangga, menempatkan titik berat bangunan rumah sedekat mungkin dengan tanah, dan meningkatkan elastisitas bangunan terhadap guncangan. (7) Pembangunan rumah non tradisional oleh masyarakat di Kobe lebih bersesuaian dengan teori siklus manajemen penanggulangan bencana Carter (1991) yang dimodifikasi oleh Munandar (2015), dari pada pembangunan rumah non tradisional oleh masyarakat di Lombok

\section{Saran}

Berdasarkan penelitian ini, disarankan kepada masyarakat di daerah rawan bencana gempa bumi dan tsunami agar memperhatikan kekokohan struktur dan kekuatan bangunan bahan bangunan apabila memdirikan bangunan. Disarankan pula agar pemerintah di Indonesia lebih banyak mensosialisasikan pengetahuan tentang teknik pembangunan rumah tahan gempa sebagai salah satu informasi penting dalam pembangunan kesejahteraan masyarakat, misalnya dengan 'Gerakan Rumah Kokoh' atau sebutan lain.

\section{DAFTAR PUSTAKA}

Sumber dari Buku :

Atep, Adtya, Barata, 2004, Dasar-dasar Pelayanan Prima, Jakarta : PT. Elex Media Komputindo.

Abbott, Patrick L.; 2004, Natural Disasters, McGraw-Hill, New York.

Adi, Isbandi Rukminto;2015, Kesejahteraan Sosial (Pekerjaan Sosial, Pembangunan Sosial, dan Kajian Pembangunan), Cetakan Ke-2, Rajawali Press, Jakarta

Badan Nasional Penanggulangan Bencana; 2012, Pedoman Penyelenggaraan Latihan Kesiapsiagaan Penanggulangan Bencana, BNPB Repubik Indonesia, Jakarta

Badan StandardisasiNasional; 2012, Tata Cara Perencanaan Ketahanan Gempa untuk Struktur Bangunan Gedung dan Non Gedung, BSN-SNI, Jakarta

Belhadj, Joshua S.; 2007, Anticipating Urban Evacuation : Planning Support System for Impact Reduction, Graduate Thesis - Master of Community Planning, University of Cincinnati.

Carter, W. Nick; 1991, Disaster 


\section{MIMBAR}

JURNAL PENELITIAN SOSIAL DAN POLITIK

Management : A Disaster Magister's Handbook, Asian Development Bank, Manila.

Hein, Carola; Resilient Tokyo : Disaster and Transformation in The Japanese City, dalam Vale, Lawrence J. \& Thomas J. Capanella (eds); 2005, The Resilient City : How Modern Cities Recover from Disaster, Oxford University Press, New York.

Mello, Anthony De, S. J.; 2005, Awareness, Doubleday, New York.

Midgley, James \& Michelle Livermore; 2005, Development Theory and Community Practice, dalam Weil, Marie (editor); 2005, The Handbook of Community Practice, Sage Publication, USA.

Munandar, Aries; 2015, Kajian Manajemen Mitigasi Bencana dan Kesiapsiagaan Penanggulangan Bencana Alam - Kasus : Penanggulangan Bencana Alam Gempa Bumi dan Tsunami di Kota Bengkulu (Disertasi), Universitas Indonesia, Jakarta.

Nagasaka, Toshinari; 2011, Development of Disaster Risk Information Platform for Enhancing Risk Governance, National Research Institute for Earth Science and Disaster Prevention (NIED), Japan.

National Research Council of The National Academies; 2004, Facing Hazards and Disasters, Understanding Human Dimensions, The National Academies Press, Washington, D.C.

Pinkowski, Jack (eds); 2008, Disaster Management Handbook, CRC Press, London.

SCDRR Bengkulu; 2010, Agenda Rekomendasi untuk Rencana Tata Ruang Wilayah Berbasis Mitigasi Bencana Provinsi Bengkulu, UNDP SCDRR Programme, Bengkulu.

Twigg, John; 2007, Karakteritik Masyarakat Tahan Bencana : Sebuah Catatan (Draft), DFID - Oxfam GB.

Vale, Lawrence J. \& Thomas J. Capanella (eds); 2005, The Resilient City : How Modern Cities Recover from Disaster, Oxford University Press, New York

\section{Situs Internet :}

https://www.youtube.com/watch?v=fYjaU1

$\underline{\mathrm{Xm} 50 \& \text { list }=\mathrm{PL} 2 \mathrm{zzeSu} 28 \mathrm{M} 88 \mathrm{sg} 2 \mathrm{DqW} \text { - }}$

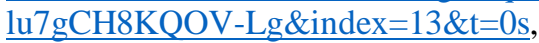

diakses 12 Oktober 2018

https://www.slideshare.net/jerlewis/kobeeart hquake?next_slideshow $=1$, diakses 4 November 2018

http://historyofgeology.fieldofscience.com/0

11/01/17-january-1995-great-kobeearthquake.html, diakses 4 November 2018

https://slideplayer.com/slide/8107202/, diakses 4 November 2018

https://www.alamy.com/stock-photokobeearthquake-1995-japan4027744.html, diakses 4 November 2018

http://www.knkx.org/post/measuringearthqu akes-more-just-one-scale, diakses 4 November 2018

https://thecarpentryway.blog/2012/09/shaknnot-stirred/, diakses 4 November 2018

http://www.solusiholcim.com/konsep/merac ang-rumah-tahan-gempa, diakses 4 November 2018

https://www.pu.go.id/berita/view/3005/konsr uksi-bangunan-tahan-gempa, diakses 4 November 2018 